\title{
Climate change and the vulnerability of electricity generation to water stress in the European Union
}

\author{
Paul Behrens $^{1,2 \star}$, Michelle T. H. van Vliet ${ }^{3}$, Tijmen Nanninga', Brid Walsh ${ }^{1}$ and João F. D. Rodrigues ${ }^{2}$
}

\begin{abstract}
Thermoelectric generation requires large amounts of water for cooling. Recent warm periods have led to curtailments in generation, highlighting concerns about security of supply. Here we assess EU-wide climate impacts for 1,326 individual thermoelectric plants and 818 water basins in 2020 and 2030. We show that, despite policy goals and a decrease in electricityrelated water withdrawal, the number of regions experiencing some reduction in power availability due to water stress rises from 47 basins to 54 basins between 2014 and 2030, with further plants planned for construction in stressed basins. We examine the reasons for these pressures by including water demand for other uses. The majority of vulnerable basins lie in the Mediterranean region, with further basins in France, Germany and Poland. We investigate four adaptations, finding that increased future seawater cooling eases some pressures. This highlights the need for an integrated, basin-level approach in energy and water policy.
\end{abstract}

$$
T^{\mathrm{h}}
$$
he electricity sector comprises at least $20 \%$ of total water withdrawal in most EU nations and approximately $55 \%$ on average across the $\mathrm{EU}^{1}$. The predominant use is for cooling within thermal power plants and takes place within a few hundred metres of the power plant itself ${ }^{2}$. Water withdrawal places local pressures on the social and ecological environment and is set to develop further under climate change as precipitation patterns change and average ambient temperatures increase $\mathrm{e}^{3-5}$.

In recent years, severe water shortages have occurred throughout the EU, for example during the summer droughts of 2003 and 2006, resulting in power curtailments ${ }^{2}$. As periods of water shortages in the EU are projected to increase due to climatic changes, understanding these impacts on the energy system becomes an essential component of EU climate change adaptation and mitigation analysis $^{6}$. The EU has positioned itself as an international leader in the development of climate-energy policy ${ }^{7}$. EU targets for renewable energy, which withdraws negligible water, would be assumed to reduce thermoelectric water stress across the EU into the future ${ }^{8}$.

Water use in power production has drawn increasing interest as researchers and policymakers have become aware of the growing sensitivity of the energy system to water availability ${ }^{9,10}$. Research has focused on water footprint analyses, where different approaches have been used to determine the water requirements of energy and fuel production both at the individual plant ${ }^{2}$, and regional level ${ }^{11}$. As the footprint of stationary electricity generation is almost entirely attributed to cooling requirements rather than fuel extraction or refinement ${ }^{2}$, studies have focused on the water footprint of electricity production (WFEP) from the power plants themselves ${ }^{11-14}$.

Connecting these footprints to water availability and temperature is an important next step to providing insight into sensitivities of the electricity system to water resources. Fricko et al. ${ }^{11}$ considered the impact of energy transitions on freshwater sustainability per broad region such as western Europe; a resolution that can support some decision-making and highlight aggregate issues, but is too coarse for specific adaptation strategies. Since the impacts of WFEP are generally local and on a water-basin level, a higher resolution allows accounting for more spatial heterogeneity ${ }^{5}$. Hejazi et al. ${ }^{15}$ used water availability and water use simulations for the twenty-first century but performed their analyses of electricity impacts on a basinaggregated level, without variability of plant units within basins. Koch and Vögele ${ }^{2}$ and van Vliet et al. ${ }^{16}$ studied impacts of climate change and changes in water resources for existing thermoelectric power at the plant level. Both of these studies do not have changes in water uses for other sectors, which may also contribute to increased water constraints for the electricity sector.

Here we investigate the combined impacts of changes in water availability and temperature due to climate change and sectoral water use changes on thermoelectric generation, and model the scope for implementing adaptation strategies. We do this at the resolution of individual basins, making this work particularly applicable to local policymaking. We present a review for 2014, 2020 and 2030 using the metric of vulnerability of thermoelectric generation to water availability (VEW). VEW gives the percentage of total water use by thermoelectric plants after all other uses have been excluded. For illustration, a VEW of $50 \%$ implies that a half of the remaining water after other uses is used in thermoelectric generation. Water use in thermoelectric generation can be characterized by a consumption component, where water is evaporated and not returned; and a withdrawal component, where water is extracted and the thermally polluted outlet water is then returned to the water source. When consumption VEW exceeds $100 \%$ there is no longer enough water available for thermoelectric power production after other uses. An annual overview is useful in giving general insight, but generally we are interested in periods where black- or brown-outs may occur due to water resources. We present an analysis of water availability and thermal quality using a monthly analysis, highlighting regions where power availability is limited. Finally, we investigate the impacts of various adaptation strategies on thermoelectric power plant vulnerability. Thus, our

\footnotetext{
${ }^{1}$ Leiden University College The Hague, Anna van Buerenplein 301, 2595 DG, The Hague, the Netherlands. ${ }^{2}$ Institute of Environmental Sciences (CML), Leiden University, PO Box 9518, 2300 RA Leiden, the Netherlands. ${ }^{3}$ Water Systems and Global change, Wageningen University, PO Box 47,6700 AA Wageningen, the Netherlands. ${ }^{*}$ e-mail: p.a.behrens@luc.leidenuniv.nl
} 
2014
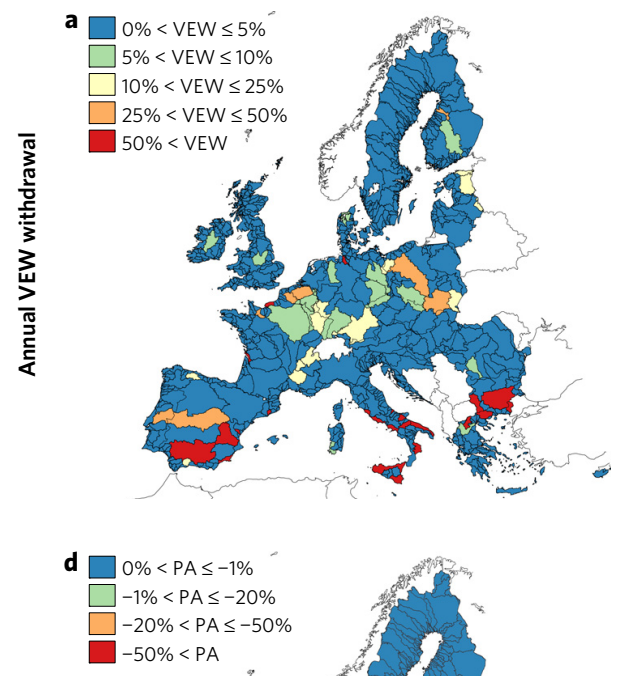

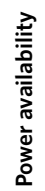
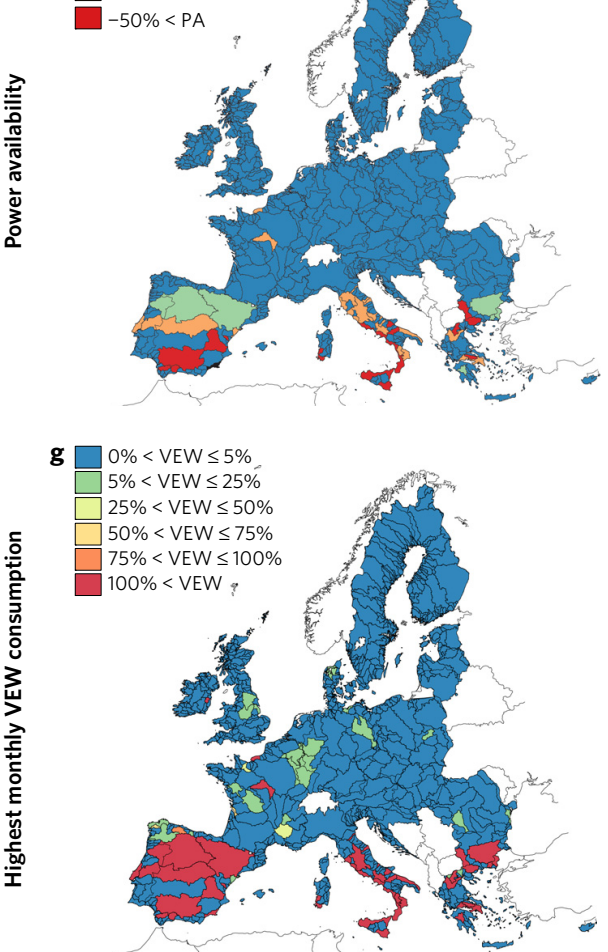

2030

b
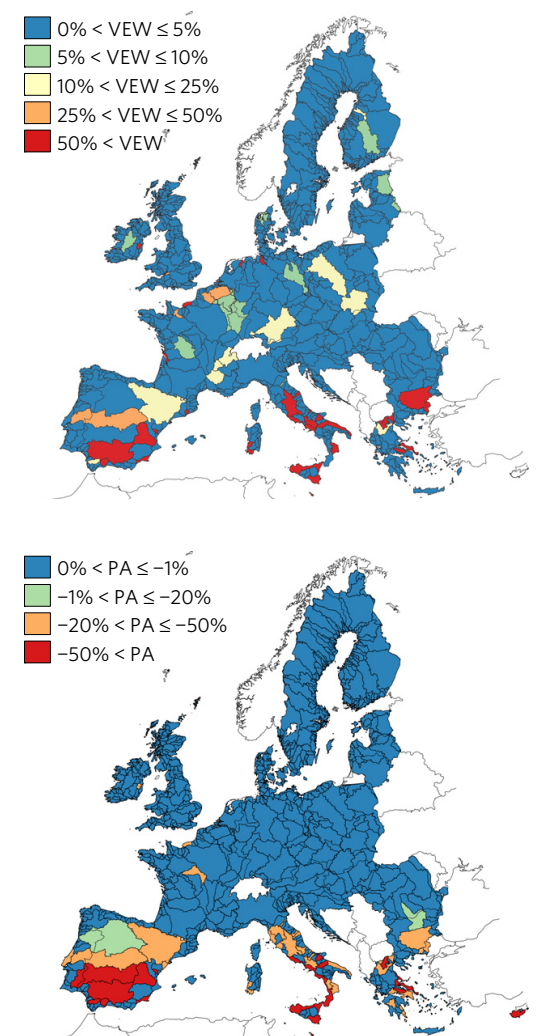

h

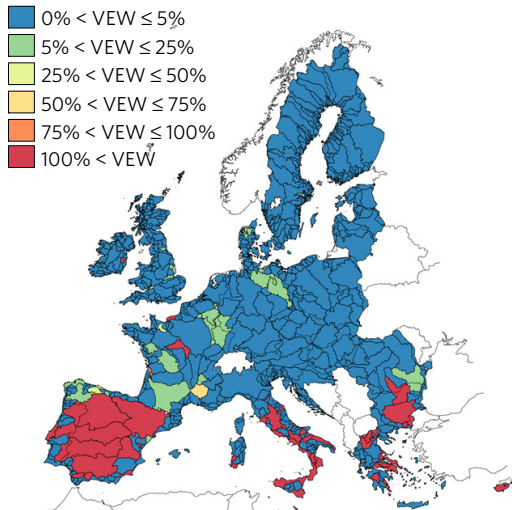

Change from 2014 to 2030

c
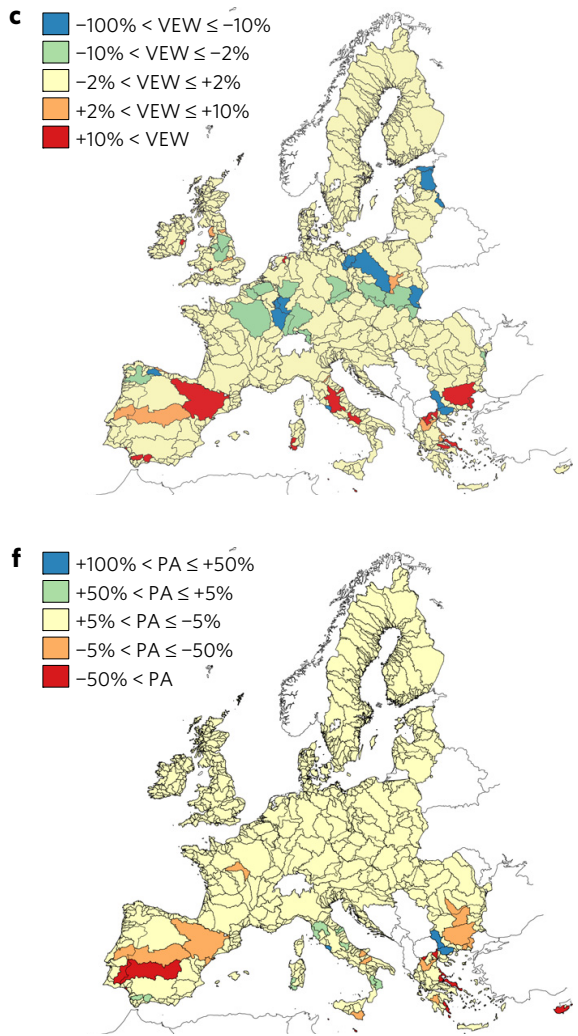

i

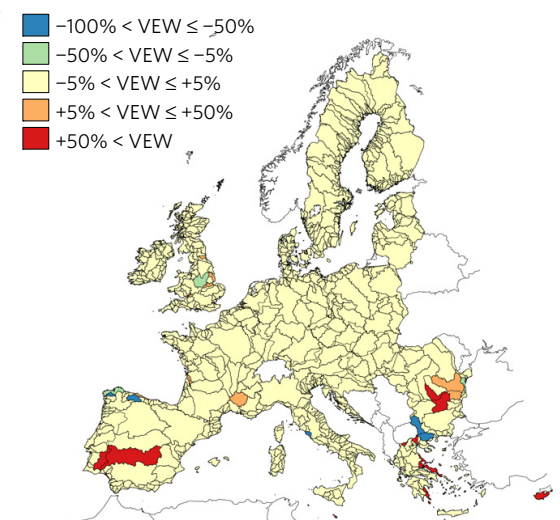

Figure 1 | Variations in water stress and power availability across the EU. a-c, The annual withdrawal VEW. d-f, The power availability due to water quantity and temperature. $\mathbf{g}$-i, Consumption VEW for the driest month.

study combines a high spatial resolution of energy and water data, climate change scenarios, other sectoral water uses and adaptation strategies at a continent-wide scale.

\section{Approach}

To build this spatially explicit, energy-water-climate model, we integrate a power plant data $\operatorname{set}^{17}$, a water quantity data $\operatorname{set}^{18}$ (both availability and demand), and a water temperature data set ${ }^{16}$. We produce an overview in 2014, and then project scenarios in 2020 and 2030. WFEP were calculated using specific fuel and cooling technologies for each power plant. The future power plant stock in 2020 and 2030 was projected by adding consented and planned power plants in the EU, and retiring plants were removed. Water data were computed at the basin level across the EU and projected to 2020 and 2030 using shared socioeconomic pathways. See Methods for a full description of the model construction.

\section{Average annual trends}

During 2014, 21\% of water was withdrawn and $3 \%$ consumed by EU thermoelectric generation. In a total of 199 water basins in which thermoelectric power is produced, $12 \%$ and $4 \%$ have a withdrawal and consumption VEW of above $50 \%$ respectively (see Supplementary Table 2 for further details). There is a large overlap between basins exhibiting high withdrawal and consumption vulnerabilities (see Fig. 1a,g), located mainly in Italy, Spain and Greece; with several others in Bulgaria, France and Germany. In Mediterranean basins, vulnerability is due to limited availability and high withdrawal. High shares in coal and nuclear generation explain the high vulnerability in Bulgaria and France respectively as these plants typically have high water demands for cooling. In Germany, vulnerabilities are driven by large withdrawals for other uses (for basin-level results, see Supplementary Tables 4-11).

Projections in 2020 and 2030 show increasing vulnerability in Mediterranean regions (see Fig. 1b). There are variations across 
northern, central and eastern Europe, but the general picture remains similar, with most basins across the EU (over $84 \%$ and $82 \%$ for 2020 and 2030 respectively) remaining within 5\% of their 2014 VEW in future years. By 2020, water withdrawals for thermoelectric generation decrease by $7 \%$, while consumption increases by $2.7 \%$, related to an increase in cooling towers compared with once-through systems. Between 2014 and 2020, 175 thermal units are scheduled for retirement, and 196 units for construction and operation, with a large switch from coal to gas $(-84$ coal and +102 gas units). No nuclear units are decommissioned in this time, and 7 more are constructed. All retired units use steam turbine technology. Among new plants, $44 \%$ are combined cycle, with the remaining 56\% split approximately equally between steam and gas turbine technologies. Despite ambitious targets for reducing EU thermal generation reliance by 2020 , changes are not sufficient to lower water vulnerability, with most basins (over $84 \%$ ) remaining within $4 \%$ of the 2014 values (see Supplementary Table 3 for further details). Some small variations are visible, with reductions in vulnerability in northern European regions, and increases in the Mediterranean. Several nations have high-vulnerability basins where further thermoelectric plant construction is planned or consented (in Spain, Bulgaria, Belgium, Germany, Greece and Poland).

By 2030, the transformation in the energy sector induced by renewable energy policies, such as increased renewable infrastructure, becomes noticeable. Compared against the 2014 baseline, the total thermoelectric generation decreases by $4 \%$. Water consumed and withdrawn decreases by $11 \%$ and $27 \%$ respectively. A total of 466 thermal units are scheduled for decommissioning, and 191 for construction. As with the period up to 2020, this is predominately a replacement of coal with gas generation ( -281 coal and +65 gas units from 2020 to 2030). Despite these efforts, as with the picture in 2020, much of the decrease in water withdrawal occurs in areas of low vulnerability with most basins remaining within 5\% of their 2014 VEW (82\%), and reductions in total water usage by the electricity sector are not in the higher-risk regions. Further basins in the Mediterranean show greater vulnerabilities, predominately in Greece and Italy, despite decommissioning of generation in several of these basins (see Fig. 1c).

\section{Monthly vulnerabilities}

The annual analysis outlines general vulnerabilities and water stresses. A further concern is periods of reduced power availability due to insufficient water availability or high water temperatures. Power availability here refers to the percentage of time thermoelectric generation is not available due to water quantity or water temperature. Regions with a power availability below $100 \%$ are generally located in the Mediterranean, specifically Portugal, Spain, Italy, Greece and Bulgaria (see Fig. 1d). There is a slight increase in basins experiencing some reduction in power availability between 2014 and 2030, from 47 basins to 54 basins (see Fig. 1f). These basins are again focused in the Mediterranean. The average power availability in basins experiencing some reduction in power availability decreases from $51 \%$ in 2014 to $48 \%$ in 2030. Focusing on the month with highest consumption, VEW highlights some further regions that may come under seasonal water stress. Regions in the Rhine, central France, northern Denmark, central/northern UK and the Polish/German border show thermoelectric consumption of between 5 and $25 \%$ of remaining water after other uses (see Fig. $1 \mathrm{~g}-\mathrm{i}$ ). Two further basins in northern and southern France show consumption VEW of 25-50\%. Withdrawal VEW shows broader sensitivities across Europe in the driest month with further basins in Poland, Germany and France showing high amounts of withdrawal (see Supplementary Fig. 9).
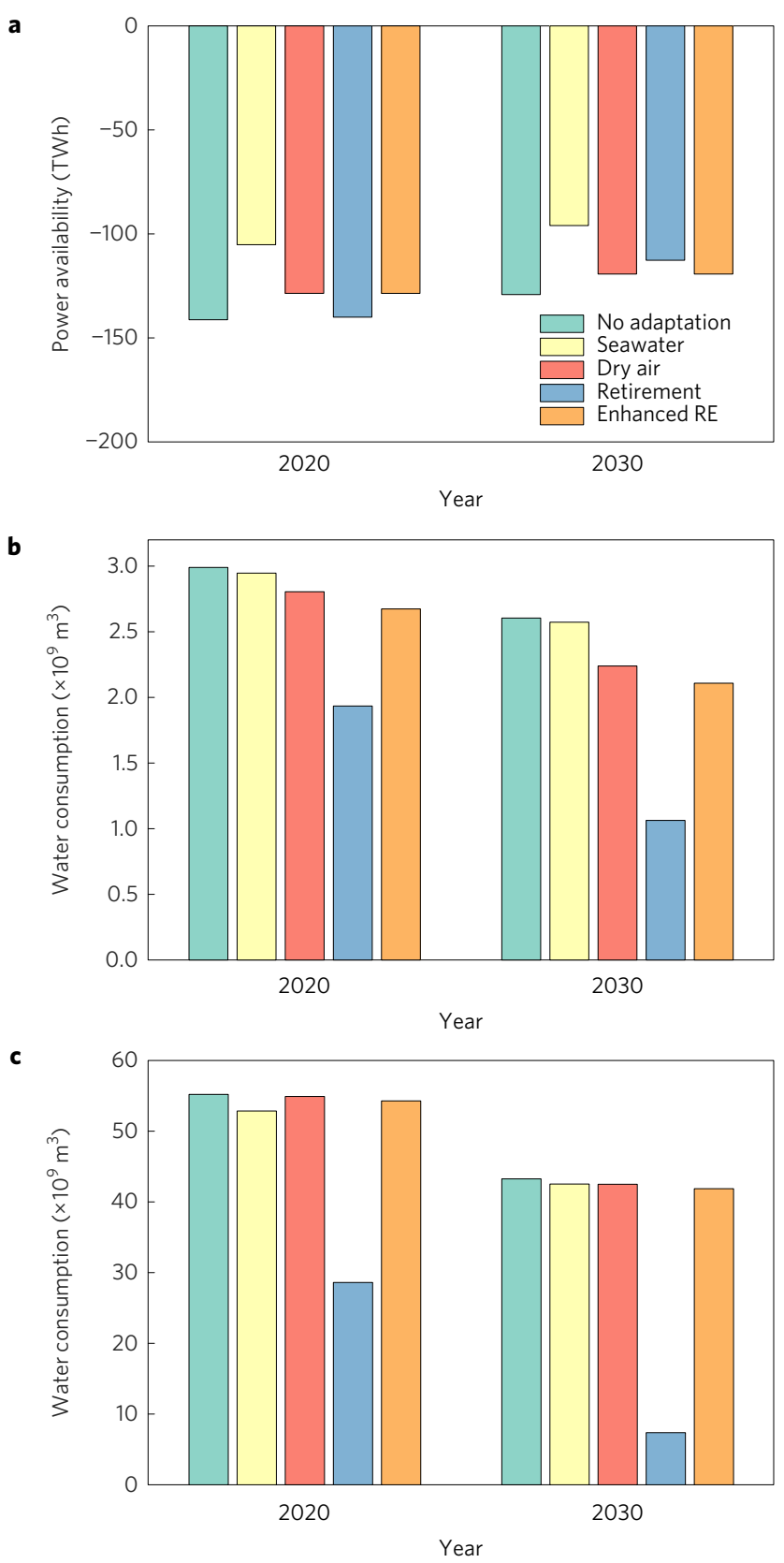

Figure $\mathbf{2}$ | Impacts of adaptation strategies across Europe. a-c, The plots show the impacts of different adaptation strategies (seawater cooling, dry air cooling, early retirement, and enhanced renewable energy generation) in 2020 and 2030 on three indicators: power availability (a), water consumption (b) and water withdrawal (c).

\section{Impacts of adaptation}

The impacts of four possible adaptation options are shown in Fig. 2. The adaptations considered are: additional seawater cooling for coastal units (seawater); fitting of dry air cooling to planned and consented units (dry air); early retirement of plants limiting lifetime to $2 / 3$ expected lifetime (retirement); switching of planned capacity to renewable generation (enhanced RE). As reductions in power availability have the largest impact in coastal Mediterranean regions, additional seawater cooling improves availability in 2020, increasing modestly in 2030 (see Fig. 2a). Other adaptations have some small impacts on availability with early retirement second most effective by 2030. In both water consumption and withdrawal, early retirement confers significant savings, with other adaptation 
options having limited impact (see Fig. 2b,c). For early retirement, withdrawal reduces by an even greater amount than consumption. Basin-level data are available in Supplementary Tables 12-14.

\section{Discussion}

Despite changes in thermoelectric power production during the period to 2030, there are limited changes to the number of basins under stress on either annual or monthly time periods. The expectation that thermoelectric generation would shift away from areas of high water stress does not hold true for planned or consented units, with further units placed in high-stress regions. The number of basins experiencing some reduction in power availability increases up to 2030. Examining the scope for the implementation of different adaption strategies reveals different priorities depending on location. Additional seawater cooling provides the largest increase in power availability in the Mediterranean due to the location of plants under threat of black-out. For water withdrawal and consumption more generally across Europe, early retirement offers the most significant changes, but also represents a significant departure from current projections to deeper reductions in emissions. Even if the benefits of adaptation strategies are clear, two prominent barriers may prevent their introduction: the cost of implementation, and the fragmentation of energy and water policy frameworks ${ }^{19}$.

Cost is a primary barrier as all adaptation strategies considered here require investment, in the form of retrofitting (seawater and dry air cooling), increased deployment of alternative energy, or in the revenue lost from retiring plants early. It may be necessary to employ market mechanisms (for example, subsidies, water prices) to encourage these vulnerability-reducing alternatives ${ }^{20,21}$. The second barrier is the fragmentation of energy and water policy frameworks. Water basins often intersect administrative and even national boundaries, making cohesive energy and water management difficult, since it is often political rather than hydrological boundaries that govern water policy ${ }^{22}$. Even cohesion within the same administrative boundary can be difficult to achieve as energy and water policy is marked by fragmentation and may sometimes seek divergent interests ${ }^{19}$. This has led to low cross-sectoral consultation, resulting in energy and water policy developed independently of each other ${ }^{19,23}$. Further, this lack of consultation and connection of policy may have inadvertent negative effects ${ }^{19}$. For example, climate mitigation strategies might have an overall negative impact on the water system ${ }^{15}$ since biofuel production and carbon capture and storage sharply increase the water demands as compared with their more carbon-intensive counterparts ${ }^{9,14,24}$. As a result of these issues, there is increased emphasis on integrated river basin management ${ }^{25-27}$, with a focus on multi-criteria decision analysis ${ }^{28}$, and adaptive management ${ }^{29}$. Such an approach can aid in the identification of future risks and facilitate a more flexible response in a fast-changing environment driven by climate change and socio-economic changes ${ }^{30}$. More generally, it can promote complementary and resilient energy and water policies, grounded in sound scientific evidence, cross-sectoral and representative stakeholder engagement, and transparency in decision-making ${ }^{31}$.

Further adaptation options, in addition to those examined, are also conceivable. Alternative options include increased water transfer between basins and improved electricity interconnection. Increased water transfer from low-vulnerability to high-vulnerability basins may significantly reduce pressure in high risk-water basins, as well as better align supply and demand. Currently, inter-basin water transfers are sometimes made for non-energy uses, for example, to supply high-density urban areas ${ }^{32}$. Such transfers have ecological impacts ${ }^{33}$ while being costly, and as such they are not commonly used in the energy sector ${ }^{1}$. An alternative to adapting the electricity generation system to local water availability is to import electricity from plants farther afield. By improving the interconnectivity of
European electricity grids ${ }^{23}$, capacity in vulnerable urban regions may be downsized or cancelled. This may result in co-benefits such as increased grid robustness, improved renewable integration, deferred capital costs and reduced health impacts through lower air pollution. This type of analysis would make for interesting future work and would require a plant-explicit and spatially explicit energy-market model.

Although this work integrates energy, water and climate models for water availability and water temperature at annual and monthly time resolution, we are unable to include all thermal power generation, with the study including $84 \%, 73 \%$ and $63 \%$ of generation in 2014, and forecasted generation in 2020 and 2030 respectively. Partly this is the omission of capacity smaller than $100 \mathrm{MW}$ (10\% in 2014), but more generally it is due to the difficulty of forecasting energy system changes. While future capacity is uncertain, this does indicate that our results should be viewed as a lower limit of vulnerability, with possible future impacts being greater. We use monthly and daily temporal resolution data for water supply/demand and water temperature, respectively. Use of these resolutions are driven by the availability of supply and demand projections at the spatial resolution of the river basins of the Aqueduct data set. These resolutions capture fast (daily) variations in water temperature (for example, during heat wave events), and slower (monthly) variations in water availability during droughts in Europe. Further increases in temporal resolution may allow for refinements and for the inclusion of an economic model incorporating sub-daily dispatch data and generation merit order.

Already, many water basins in the EU experience vulnerability of electricity generation to water scarcity. Climate change is projected to have a significant impact on the quantity and temperature of water in the EU. These changes will further exacerbate existing vulnerabilities in the energy-water nexus. Policymakers and industry will need to be cognisant of these risks and to implement solutions in advance of these impacts.

\section{Methods}

Overview. We build an integrated energy-water-climate model that, calibrated with appropriate high-resolution data, allows us to calculate the vulnerability of energy generation to water availability across all water basins in the EU. We perform this analysis for a reference year, 2014, and for projected scenarios in 2020 and 2030. We assess the scope for implementing four adaptation strategies: additional seawater cooling, dry air cooling retrofits, early retirement and enhanced renewable energy roll-out. See Supplementary Fig. 1 for a schematic of the modelling framework.

Vulnerability to water availability. Here we focus on the use of freshwater as opposed to saline or brackish water, as this has competition with other sectoral water uses and is critical to natural systems. Water extracted for thermoelectric cooling may be thermally polluted, held, and then returned to the source, or evaporated and not returned. The latter use is herein termed consumption, and the total water use incorporating both types is termed withdrawal. The consumption of a large fraction of freshwater may breach renewably available flows. The withdrawal of a large fraction of water may breach thermal quality standards and reduce short-term availability of water in the rest of the basin ${ }^{22}$. In this study, we calculate the water footprint of electricity production (WFEP) separately for withdrawal and consumption using equation (1):

WFEP $=$ Production $\times$ Footprint Factor $\times$ time

where production is given in $\mathrm{GJ} \mathrm{s}{ }^{-1}$, footprint factor in $\mathrm{m}^{3} \mathrm{GJ}^{-1}$, and time in seconds. WFEP over the year and the month are calculated for each power unit and aggregated to the basin level for both consumption and withdrawal volumes per time unit. Footprint factors depend on fuel, cooling equipment and turbine type, and are collected from the literature (see Supplementary Table 1). We assume that water within the local basin will be used in preference to inter-basin transfers since for most EU nations over $99 \%$ of water extracted for electricity production is from the same basin ${ }^{1}$.

We define a metric for the vulnerability of electricity generation to water availability (VEW for short). VEW is defined as the ratio of water extracted by 
power plants to the remaining available water in a given water basin, given by equation (2): WFEP

$\mathrm{VEW}=\frac{\mathrm{WFEP}}{\text { (water availability }- \text { non-energy water use) }}$

For illustration, a value of 0.1 in withdrawal VEW indicates that every year or month $10 \%$ of a water basin's remaining freshwater after other uses is withdrawn by thermoelectric plants. Conversely, this metric can also be interpreted as the vulnerability of the water basin to power generation. VEW is defined for both water withdrawal and consumption.

Thermoelectric data. Production in each basin was obtained from the Platts World Electric Power Plants database (WEPP) ${ }^{17}$. Plant data were filtered to include EU-based, thermal generation greater than $100 \mathrm{MW}$. Installations below this capacity generally have no available cooling-system information ${ }^{17}$, have non-representative load factors ${ }^{34}$, and by definition include micro-generation. For the EU in 2014, data for 49,980 units were available, with 3,725 larger than $100 \mathrm{MW}$. This was further filtered for thermal generation, omitting renewables and hydropower, leaving 1,305 plants with a total electrical generation in 2014 of 7,344 PJ. This filtered selection of plants is highly representative in 2014, accounting for $90 \%$ of total thermal electricity generation ${ }^{35}$. Plants were linked with basins with geographic coordinates available in the WEPP and CARMA databases ${ }^{36}$. Where locations were not available, the closest urban area to the unit was used. We omit renewable generation as it uses negligible amounts of water ${ }^{10}$. We also omit hydropower since reservoirs have multiple functions in water supply and flood control ${ }^{37,38}$. As such, water use for hydroelectricity is misleading, and we align with many other studies by excluding hydropower from the analysis ${ }^{10,14,39}$. As WEPP reports capacity, load factors were applied across power plants with the same fuel type. Factors for each generation type were: solids (coal and peat) 0.52 , gas (blast furnace gas, coal syngas, natural gas, refinery off-gas, gasified crude oil) 0.39 , liquid (liquefied natural gas, liquefied petroleum gas, fuel oil) 0.12 , and nuclear (uranium) 0.7 (refs 36,40-43). Supplementary Fig. 2 shows the locations and breakdown of different generation types in 2014 .

The stock of future plants was estimated by combining existing plants with those planned, consented or under construction by the target year. We exclude plants currently operating but decommissioned before the target year. The expected decommissioning year of a plant was calculated as the construction year plus the average lifetime of the power plant by fuel type. On the basis of the literature, we used the following average lifetimes in years: solid 50, gas 45, liquid 50 , and nuclear 60 (refs 44-47). For the 2020 scenario, 1,326 plants with a generation of 7,935 PJ were included. For the 2030 scenario 1,030 plants with a generation of 7,074 PJ were included. This represents $76 \%$ and $64 \%$ of forecasted thermal generation in 2020 and 2030 respectively ${ }^{34}$.

Water data. The World Resources Institute (WRI) provides a global water risk atlas on a basin level for 2010, and projections for 2020 and $2030^{18}$. Spatially, the data set begins at a basin-level resolution with a mean area of between $5,276 \mathrm{~km}^{2}$. Flows between basins are captured by a flow accumulation approach, and water use and projections are computed at the sub-basin level. We used data for a total of 818 distinct EU basins. The data set includes freshwater availability (the volume of freshwater available for extraction), water withdrawal (total water extracted from water basin) and water consumption (total water consumed from water basin). Baseline data for 2014 are visualized in Supplementary Fig. 3 and lowest monthly water availability visualized in Supplementary Fig. 4. Future scenarios were modelled under three scenarios developed by $\mathrm{WRI}^{4}$ : pessimistic, business as usual (BAU) and optimistic. These scenarios were assembled using three data sets: the Intergovernmental Panel on Climate Change's Representative Concentration Pathways (RCPs) ${ }^{48}$; the Shared Socio-Economic Pathways (SSPs) ${ }^{49}$; and the Coupled Model Intercomparison Project Phase 5 global circulation model $^{50}$. RCPs are pathways describing the increase in radiative forcing due to climate change, the two used here are: RCP8.5, a BAU pathway of relatively unconstrained emissions resulting in a radiative forcing of $8.5 \mathrm{~W} \mathrm{~m}^{-2}$ and temperature increases of $2.6-4.8^{\circ} \mathrm{C}$ by 2100 relative to $1986-2005$; and RCP4.5, a cautiously optimistic pathway resulting in a radiative forcing of $4.5 \mathrm{~W} \mathrm{~m}^{-2}$ and temperature increases of $1.1-2.6^{\circ} \mathrm{C}$. Monthly variations in water availability across the EU are shown for each year in Supplementary Fig. 5. SSPs are pathways of socio-economic drivers, the two included here are: SSP2, a BAU pathway; and SSP3, a pessimistic pathway with higher population growth, lower GDP growth and a lower rate of urbanization. These are then combined to give three water-system scenarios, pessimistic (RCP8.5 and SSP3), BAU (RCP8.5 and SSP2) and optimistic (RCP4.5 and SSP2), similar to other work ${ }^{51}$. We use only the BAU scenario in the main results as there is very little variation between scenarios by 2030. The baseline year of the water-basin Aqueduct database is 2010 whereas the energy WEPP database is 2014 . Hence, the water availability, withdrawal and consumption reported in the baseline year of our study (2014) was obtained from a linear interpolation between 2010 and 2020. Water availability is projected to change significantly even in the optimistic scenarios. This is largely due to the fact that the anthropogenic forces of climate change and increases in population and energy demand cannot be completely halted before 2020 or 2030 even under the optimistic scenarios ${ }^{16}$. Finally, daily river water temperature was used to further refine power availability estimates. For any period where water consumption did not already exceed water availability, if the temperature exceeded $23^{\circ} \mathrm{C}$, generation was also considered to be unavailable (see Supplementary Note 1 for further information). Supplementary Fig. 6 shows the percentage of days exceeding the threshold in the month of lowest water availability, and Supplementary Fig. 7 shows the variation in water temperature across the EU for each year.

Water footprint factors. The water footprint factor is the water withdrawn or consumed per unit of energy, depending on fuel, turbine and cooling type ${ }^{2}$. Hence, besides the four fuel types described above, we also consider three turbine technologies (steam turbine, combined cycle and gas turbine) and four cooling technologies (cooling tower, once-through freshwater, cooling pond and dry cooling). See Supplementary Note 2 for a further description of cooling technologies. In the filtered WEPP data set used herein, a total of $81 \%$ of the stock of non-nuclear power plants in 2014 use steam turbines, with a further $10 \%$ using gas turbines and the remaining $9 \%$ using combined-cycle technologies. Cooling methods are dominated by cooling towers (51\%) and once-through freshwater (37\%), with $11 \%$ cooled by air (predominantly gas turbines) and less than $1 \%$ using a cooling pond. To obtain disaggregated water footprint factors on fuel type, turbine technology and cooling technology we combined different sources, reported in Supplementary Table 1, which also reports the final coefficients we obtained. The water footprint factors were then multiplied by energy generated, yielding a total water use for energy generated per unit (WFEP per unit). WFEP was computed for the year, and for the month for each unit. Finally, the WFEPs for all units in each basin were aggregated to find the total water use by thermoelectric power.

Adaptation strategies. Finally, we consider four adaptation strategies of power generation to water supply: a further switch to seawater cooling, retrofitting of plants to dry air cooling, early retirement of existing power plants and cancellation of planned plants in favour of renewables. Expanded use of seawater cooling is a viable option as many plants in the EU already utilize once-through saline water cooling. We model this adaptation strategy such that all power plants within $10 \mathrm{~km}$ are retrofitted to use seawater. The WFEPs of these plants are then reduced to zero. This adaptation strategy results in negligible water extraction from the water basin, as well as co-benefits such as potential efficiency improvements due to a larger volume of water available for cooling ${ }^{52}$. For dry air retrofits, we assume that all planned or consented developments implement dry air cooling instead of the planned cooling type. Although this adaptation type does confer reductions in power output of $10-15 \%$ during the hottest periods due to efficiency losses ${ }^{53}$, we do not model the additional capacity required during these periods. The early retirement of thermal power plant stock assumes that due to additional policy pressures encouraging alternative energy strategies, plant lifetimes are one-third shorter than the literature suggests, giving average generation lifetimes for solid fuels of 33 years, gaseous fuels 30 years, liquid fuels 33 years and nuclear fuels 40 years. This means that older plants with lower water and energy efficiency are retired first. This early decommissioning would confer large capital costs, and put pressure on energy systems to provide the forgone capacity, so this strategy corresponds to an increased future response of policymakers to environmental concerns. Finally, the increased renewable energy roll-out assumes that all planned thermal construction by each target year is cancelled, in preference for renewable alternatives. For this strategy, we simply remove these planned plants from the future energy system. It is important to note that we do not remove consented power plant construction, which we assume will be constructed. Consents represent large investments in public and private time and money, and are unlikely to go unused. This scenario represents an enhanced renewable energy scenario where further alternatives to thermal generation are implemented.

Regional population and GDP data. To compare vulnerabilities in different basins with other factors, population and GDP (gross domestic product) statistics were collected from Eurostat data, reported at the level of NUTS3 regions ${ }^{54}$. For consistency, they were mapped to water basins by calculating the overlap between each NUTS region and water basin and making an area-weighted average. Supplementary Table 2 gives EU overview statistics for basins within given vulnerability thresholds.

Code availability. Example Matlab scripts used in the production of this analysis are available at github.com/PaulBehrens/WaterEnergyClimate.git.

Data availability. The data that support the plots within this paper and other findings of this study are available from the corresponding author upon reasonable request. World Resource Institute data on annual timescales are openly available for download ${ }^{55}$. 
Received 5 September 2016; accepted 14 June 2017; published 24 July 2017

\section{References}

1. Water Use in Industry (Eurostat, 2014); http://ec.europa.eu/eurostat/statisticsexplained/index.php/Water_use_in_industry

2. Koch, H. \& Vögele, S. Dynamic modelling of water demand, water availability and adaptation strategies for power plants to global change. Ecol. Econ. 68, 2031-2039 (2009).

3. Proust, K. et al. Climate, Energy and Water; Accounting for the Links (Land and Water, 2007); http://s3.amazonaws.com/zanran_storage/ www.crdc.com.au/ContentPages/44777431.pdf

4. Luck, M., Landis, M. \& Gassert, F. Aqueduct Water Stress Projections: Decadal Projections of Water Supply and Demand Using CMIP5 GMs (World Resources Institute, 2015); https://www.wri.org/sites/default/files/ aqueduct-water-stress-projections-technical-note.pdf

5. Holland, R. A. et al. Global impacts of energy demand on the freshwater resources of nations. Proc. Natl Acad. Sci. USA 112, E6707-E6716 (2015).

6. Russo, S., Dosio, A., Sterl, A., Barbosa, P. \& Vogt, J. Projection of occurrence of extreme dry-wet years and seasons in Europe with stationary and nonstationary Standardized Precipitation Indices. J. Geophys. Res. 118, 7628-7639 (2013).

7. Scott, J. \& Rajamani, L. EU climate change unilateralism. Eur. J. Int. Law 23, 469-494 (2012).

8. Limiting Global Climate Change to 2 Degrees Celsius - The way Ahead for 2020 and Beyond (Commission of the European Communities, 2007).

9. Byers, E. A., Hall, J. W., Amezaga, J. M., O’Donnell, G. M. \& Leathard, A. Water and climate risks to power generation with carbon capture and storage. Environ. Res. Lett. 11, 024011 (2016).

10. Macknick, J., Newmark, R., Heath, G. \& Hallett, K. C. Operational water consumption and withdrawal factors for electricity generating technologies: a review of existing literature. Environ. Res. Lett. 7, 045802 (2012).

11. Fricko, O. et al. Energy sector water use implications of a 2-degree climate policy. Environ. Res. Lett. 11, 034011 (2016).

12. Okadera, T., Chontanawat, J. \& Gheewala, S. H. Water footprint for energy production and supply in Thailand. Energy 77, 49-56 (2014).

13. Pfister, S., Saner, D. \& Koehler, A. The environmental relevance of freshwater consumption in global power production. Int. J. Life Cycle Assess. 16, 580-591 (2011).

14. Spang, E. S., Moomaw, W. R., Gallagher, K. S., Kirshen, P. H. \& Marks, D. H. The water consumption of energy production: an international comparison. Environ. Res. Lett. 9, 105002 (2014).

15. Hejazi, M. I. et al. 21st century United States emissions mitigation could increase water stress more than the climate change it is mitigating. Proc. Natl Acad. Sci. USA 112, 10635-10640 (2015).

16. Van Vliet, M. T. H., Wiberg, D., Leduc, S. \& Riahi, K. Power-generation system vulnerability and adaptation to changes in climate and water resources. Nat. Clim. Change 6, 375-380 (2016).

17. Database Description and Research Methodology UDI World Electric Power Plants Database. 1 (Platts, 2015); https://www.platts.com/ im.platts.content/downloads/udi/wepp/descmeth.pdf

18. Gassert, F., Landis, M., Luck, M., Reig, P. \& Shiao, T. Aqueduct Global Maps 2.1 (World Resources Institute, 2015); https://www.wri.org/ sites/default/files/Aqueduct_Global_Maps_2.1.pdf

19. Hussey, K. \& Pittock, J. The energy-water nexus: managing the links between energy and water for a sustainable future. Ecol. Soc. 17, 1-9 (2012).

20. Fais, B., Blesl, M., Fahl, U. \& Voß, A. Comparing different support schemes for renewable electricity in the scope of an energy systems analysis. Appl. Energy 131, 479-489 (2014).

21. Behrens, P., Rodrigues, J., Brás, T. \& Silva, C. Environmental, economic, and social impacts of feed-in tariffs: a Portuguese perspective 2000-2010. Appl. Energy 173, 309-319 (2016).

22. King, C. W., Stillwell, A. S., Twomey, K. M. \& Webber, M. E. Coherence between water and energy policies. Nat. Resour. J. 53, 117-215 (2013).

23. Becker, S., Rodriguez, R. A., Andresen, G. B., Schramm, S. \& Greiner, M. Transmission grid extensions during the build-up of a fully renewable pan-European electricity supply. Energy 64, 404-418 (2014).

24. Wu, M. \& Chiu, Y. Consumptive Water Use in the Production of Ethanol and Petroleum Gasoline 2011 Update Report number ANL/ESD/09-1 (Argonne National Laboratory, 2011).

25. The Dublin Statement on Water and Sustainable Development 1-55 (World Meteorological Organization, 1992); http://www.wmo.int/pages/ prog/hwrp/documents/english/icwedece.html.

26. Rijke, J., van Herk, S., Zevenbergen, C. \& Ashley, R. Room for the river: delivering integrated river basin management in the Netherlands. Int. J. River Basin Manage. 10, 369-382 (2012).
27. Nielsen, H. Ø., Frederiksen, P., Saarikoski, H., Rytkönen, A.-M. \& Pedersen, A. B. How different institutional arrangements promote integrated river basin management. Evidence from the Baltic Sea region. Land Use Policy 30, 437-445 (2013).

28. Linkov, I. et al. From comparative risk assessment to multi-criteria decision analysis and adaptive management: recent developments and applications. Environ. Int. 32, 1072-1093 (2006).

29. Pahl-Wostl, C., Lebel, L., Knieper, C. \& Nikitina, E. From applying panaceas to mastering complexity: toward adaptive water governance in river basins. Environ. Sci. Policy 23, 24-34 (2012).

30. Pahl-Wostl, C. Transitions towards adaptive management of water facing climate and global change. Water Resour. Manag. 21, 49-62 (2007).

31. Mostert, E. et al. Social learning in European river-basin management: barriers and fostering mechanisms from 10 river basins. Ecol. Soc. 12, 19 (2007).

32. Collins, R., Kristensen, P. \& Thyssen, N. Water Resources Across Europe-Confronting Water Scarcity and Drought EEA Report 2/2009. (Resilience Alliance, 2009); http://dx.doi.org/10.2800/16803

33. Meador, M. Inter-basin water transfer: ecological concerns. Fisheries 17, 17-22 (1992).

34. Capros, P., Mantzos, L., Papandreou, V. \& Tasios, N. European Energy and Transport-Trends to 2030 1-158 (Directorate-General for Energy and Transport, 2007).

35. Electricity Production and Supply Statistics (European Commission, 2014) http://ec.europa.eu/eurostat/statistics-explained/index.php/ Electricity_production_and_supply_statistics

36. CARMA Database v3.0 (Centre for Global Development, 2009) http://www.carma.org

37. Dams and Development: A New Framework for Decision-Making 58-63 (World Commission on Dams, 2001); http://pubs.iied.org/ pdfs/9126IIED.pdf

38. Fthenakis, V. \& Kim, H. C. Life-cycle uses of water in US electricity generation. Renew. Sustain. Energy Rev. 14, 2039-2048 (2010).

39. Elcock, D. Future US water consumption: the role of energy production. J. Am Water Resour. Assoc. 46, 447-460 (2010).

40. Joint Research Centre. Analysis of Energy Saving Potentials in Energy Generation: Final Results (Institute for Energy and Transport at the European Commission, 2012); http://dx.doi.org/doi:10.2790/58574

41. MacLeay, I., Harris, K. \& Annut, A. Digest of UK Energy Statistics 2013 1-268 (Department of Energy \& Climate Change, National Statistics, 2013); https://www.gov.uk/government/uploads/system/uploads/attachment_data/ file/279523/DUKES_2013_published_version.pdf

42. Moreno, F. \& Martinez-Val, J. M. Collateral effects of renewable energies deployment in Spain: impact on thermal power plants performance and management. Energy Policy 39, 6561-6574 (2011).

43. Honoré, A. The Outlook for Natural Gas Demand in Europe (Oxford Institute for Energy Studies, 2014); https://www.oxfordenergy.org/wpcms/wpcontent/uploads/2014/06/NG-87.pdf

44. Davis, S. J. \& Socolow, H. Commitment accounting of $\mathrm{CO}_{2}$ emissions. Environ. Res. Lett. 9, 084018 (2014).

45. Schwarz, H. G. Modernisation of existing and new construction of power plants in Germany: results of an optimisation model. Energy Econ. 27, 113-137 (2005)

46. Rintamaa, R. \& Aho-Mantila, I. Plant life management and modernisation: research challenges in the EU. Nucl. Eng. Des. 241, 3389-3394 (2011).

47. Venkatesh, A., Jaramillo, P., Griffin, W. M. \& Matthews, H. S. Implications of near-term coal power plant retirement for $\mathrm{SO}_{2}$ and $\mathrm{NO}_{\mathrm{x}}$ and life cycle GHG emissions. Environ. Sci. Technol. 46, 9838-9845 (2012).

48. Collins, M. et al. in Climate Change 2013: The Physical Science Basis (eds Stocker, T. F. et al.) 1029-1136 (IPCC, Cambridge Univ. Press, 2013).

49. O’Neill, B. et al. A new scenario framework for climate change research: the concept of shared socioeconomic pathways. Climatic Change 122, 387-400 (2014)

50. Taylor, K. E., Stouffer, R. J. \& Meehl, G. A. An overview of CMIP5 and the experiment design. Bull. Am. Meteorol. Soc. 93, 485-498 (2012).

51. Van Vuuren, D. P. et al. The use of scenarios as the basis for combined assessment of climate change mitigation and adaptation. Glob. Environ. Change 21, 575-591 (2011).

52. Macknick, J., Sattler, S., Averyt, K., Clemmer, S. \& Rogers, J. The water implications of generating electricity: water use across the United States based on different electricity pathways through 2050. Environ. Res. Lett. 7, 045803 (2012).

53. Kelly, B. Nexant Parabolic Trough Solar Power Plant Systems Analysis Task 2: Comparison of Wet and Dry Rankine Cycle Heat Rejection (NREL, 2006); http://www.nrel.gov/docs/fy06osti/40163.pdf 
54. Nomenclature of Territorial Units for Statistics (Eurostat 2017); http://ec.europa.eu/eurostat/web/nuts/overview

55. Gassert, F., Landis, M., Luck, M., Reig, P. \& Shiao, T. Aqueduct Metadata Document Aqueduct Global Maps v.2. 0 1-20 (World Resources Institute, 2013).

\section{Acknowledgements}

We thank the World Resources Institute and R. Hofste for their support.

\section{Author contributions}

P.B. designed the study and performed analysis. M.T.H.v.V. provided specific data and input on drafting. J.F.D.R. assisted with the analysis. T.N. assisted in preparing the data set of power plants. P.B. drafted the manuscript. All authors discussed the results and contributed to the manuscript.

\section{Additional information}

Supplementary information is available for this paper.

Reprints and permissions information is available at www.nature.com/reprints.

Correspondence and requests for materials should be addressed to P.B.

How to cite this article: Behrens, P., van Vliet, M. T. H., Nanninga, T., Walsh, B. \& Rodrigues, J. F. D. Climate change and the vulnerability of electricity generation to water stress in the European Union. Nat. Energy 2, 17114 (2017).

Publisher's note: Springer Nature remains neutral with regard to jurisdictional claims in published maps and institutional affiliations.

\section{Competing interests}

The authors declare no competing financial interests. 